\title{
RECICLAGEM E ECONOMIA SOLIDÁRIA: análise das dimensões estruturais dos empreendimentos coletivos de catadores no Brasil
}

\author{
RECYCLING AND SOLIDARITY ECONOMY: \\ the analysis of the structural dimensions of collective \\ enterprises of pickers in Brazil
}

\author{
Rodrigo Mota *
}

\begin{abstract}
Resumo
O objetivo deste estudo foi analisar as características estruturais dos empreendimentos coletivos de catadores de materiais recicláveis no Brasil, abordando questões sobre sua organização administrativa e sua eficiência econômica. Para isso, além de uma ampla bibliografia que trata o tema, foram consultados também os dados referentes a duas pesquisas de âmbito nacional que fornecem um panorama analítico importante sobre as dimensões estruturais desses empreendimentos. De maneira geral, o segmento social dos catadores envolve pessoas que se encontram em situação de precariedade laboral, apesar de ser uma atividade reconhecidamente benéfica para a sociedade. Todas as informações identificadas demonstram que os empreendimentos são marcados por uma grande heterogeneidade estrutural, em um conjunto de fatores que impacta diretamente no nível de eficiência, produtividade do trabalho, nas condições de trabalho e, consequentemente, na satisfação dos catadores em fazer parte de um empreendimento coletivo.
\end{abstract}

Palavras chave: Economia solidária. Reciclagem. Catadores. Organização coletiva.

\begin{abstract}
The aim of this study was to analyze the structural characteristics of collective enterprises of pickers of recyclable material in Brazil, addressing questions about its administrative organization and its economic efficiency. Therefore, in addition to a wide bibliography that deals with the topic, it was also consulted the data from two nationwide surveys that provide important analytical overview on the structural dimensions of these enterprises. In general, the social segment of collectors involves people who are in situations of job insecurity, although practicing an admittedly beneficial activity for society. All information identified demonstrate that the developments are marked by a large structural heterogeneity, in a set of factors that directly impacts on the level of efficiency, labor productivity, working conditions and hence the satisfaction of collectors in be part of a collective enterprise.
\end{abstract}

Keywords: Solidarity economy. Recycling. Pickers. Collective organization.

\footnotetext{
* Instituto de Pesquisa Econômica Aplicada (Ipea), Brasil. E-mail: sandroecbr@yahoo.com.br
} 


\section{Introdução}

O segmento social dos catadores de material reciclável integra o cenário urbano, no Brasil, há muito anos, convivendo em espaços espalhados nas pequenas e grandes cidades. De maneira geral, trata-se de pessoas que se inserem nessa atividade por ser a única possível para realizar sua sobrevivência através do trabalho, ou pelo menos aquela mais viável, no contexto das necessidades imediatas, como alternativa às restrições que lhes são infringidas pela dinâmica do mercado de trabalho.

Para enfrentar essa dura realidade de pobreza e exclusão social, um contingente considerável de catadores, envolvidos em diferentes elos da cadeia da reciclagem, tem buscado se organizar mediante diferentes estratégias de ação coletiva. Essa organização pode ser observada tanto em termos de representação política, com a mobilização dos trabalhadores e seus familiares em torno de uma categoria profissional, em busca de reconhecimento social e direitos de cidadania, quanto em termos econômico-produtivos, no intuito de somar forças, por meio do trabalho associativo, em empreendimentos econômicos.

Esses empreendimentos econômicos associativos, embora atuem diretamente no mercado para a comercialização de seus produtos, têm algumas particularidades em relação a uma empresa comum. A principal diferenciação refere-se ao fato de serem organizações de pessoas, e não de capital. Isto é, os empreendimentos associativos visam atender aos objetivos de seu quadro social, de acordo com a natureza econômica de suas atividades, enquanto uma empresa visa auferir retorno de uma determinada quantia de capital investido por seus proprietários. Por isso são enquadrados no campo da "economia solidária" (SILVA, 2017a; 2017b). Isso não quer dizer, porém, que um empreendimento associativo não deva fazer uso de técnicas de gestão voltadas a proporcionar maior retorno financeiro em sua atividade. Pelo contrário, quanto melhor o resultado econômico, maior a capacidade de atendimento das expectativas dos trabalhadores envolvidos. No entanto, a busca pelo excedente não é um fim em si mesmo, uma vez que ela está condicionada ao interesse geral dos associados. Por isso, a gestão coletiva e democrática é ressaltada como um elemento fundamental da operacionalização desses empreendimentos, para estipular diretrizes internas de atuação que visem equilibrar a relação entre produção de excedente e retorno social (GAIGER, 2013). Ou seja, no caso de empreendimentos coletivos sob o paradigma da economia solidária, as dimensões econômica, social e política estão fortemente imbricadas.

No caso específico dos empreendimentos coletivos compostos por catadores de material reciclável, há uma série de fatores que condiciona diretamente seu potencial econômico, fatores estes que vão muito além das características inerentes à cadeia de valor da reciclagem. A própria complexidade das contingências sociais que levam muitos trabalhadores a se inserir nesse tipo de atividade já aponta para uma heterogeneidade muito grande em termos da capacidade organizativa para gerar e gerir coletivamente um empreendimento econômico. 
Nesse sentido, o objetivo desta pesquisa foi analisar, em um plano mais genérico, as características estruturais desses empreendimentos espalhados em diferentes locais do território nacional, tendo como foco analítico sua organização administrativa e sua eficiência econômica, isto é, os principais fatores que podem ser apontados como definidores de sua heterogeneidade estrutural e dos diferenciais de eficiência econômica. Para isso, além de uma consulta extensiva da bibliografia disponível sobre o tema, foram consultados também os dados referentes a duas pesquisas de âmbito nacional que fornecem um panorama analítico importante das dimensões estruturais desses empreendimentos.

Este texto está organizado em cinco seções, incluindo a introdução. $\mathrm{Na}$ seção dois são discutidos os principais aspectos referentes à cadeia de valor da reciclagem e como se inserem os catadores. Na seção três, são apresentados os conceitos fundamentais que envolvem o paradigma da economia solidária, na perspectiva do trabalho associativo e autogestionário em grupos populares. Posteriormente, são analisados os aspectos que determinam as condições de trabalho em empreendimentos coletivos de catadores de material reciclável e seus aspectos estruturais. Por fim, são tecidas algumas considerações.

\section{A cadeia da reciclagem e a inserção social dos catadores}

A trajetória da atividade de coleta e reciclagem de resíduos sólidos no Brasil acompanha o próprio processo de industrialização e urbanização acelerada com o intenso impulso migratório a partir da segunda metade do século XX. Como toda atividade produtiva está sujeita a 'vazamentos', por meio dos descartes que ela mesma gera, o aumento do consumo contribuiu enormemente para a elevação da quantidade e da diversidade de resíduos lançados no ambiente, além de sua concentração espacial, sobretudo nas grandes capitais e regiões metropolitanas (FÉ; FARIA, 2011).

Porém, estabelecer um cálculo do potencial econômico total da reciclagem no Brasil é uma tarefa difícil, mesmo porque o setor ainda não é explorado de forma sistemática em todo o território nacional. Estimativas de alguns órgãos de pesquisa apontam que apenas $13 \%$ do total de resíduos urbanos gerados no país são encaminhados para reciclagem, e que os benefícios econômicos auferidos com o setor poderiam ser, no mínimo, seis vezes maiores com relação ao que se tem registrado atualmente (SILVA; GOES; ALVAREZ, 2013).

A reciclagem não é caracterizada apenas por benefícios econômicos. Nos últimos anos, com a importância que vem tomando a temática ambiental em todo o mundo, esse setor se fortaleceu ainda mais na opinião pública. Os benefícios ambientais associados à reciclagem podem se dar em diferentes dimensões, uma vez que ela evita uma série de externalidades negativas próprias do processo produtivo, tais como: perda de recursos madeireiros e não madeireiros; danos ao ciclo hidrológico; perda de biodiversidade; impactos sobre a saúde ocupacional; danos à saúde humana por emissões atmosféricas; redução do consumo de energia, entre outras. Sob tal perspectiva, a reciclagem possibilita um "triplo efeito" de redução das externalidades negativas sobre o meio ambiente, uma vez que: i) 
contribui para a melhora da qualidade ambiental urbana; e ii) reduz as pressões sobre os ecossistemas naturais de onde provêm aquelas matérias primas virgens e demais insumos substituíveis por materiais reciclados; e iii) reduz o acúmulo de resíduos em aterros sanitários (DAMÁSIO, 2010; INSTITUTO DE PESQUISA ECONÔMICA APLICADA, 2011). Para potencializar os ganhos referentes a essa atividade, um dos principais instrumentos a serem considerados é a instalação de programas de "coleta seletiva" nos municípios brasileiros, envolvendo as etapas de coleta, transporte, tratamento e triagem do lixo gerado por famílias e empresas. No entanto, embora a questão da destinação adequada dos resíduos sólidos urbanos seja objeto de debate para a construção da agenda governamental desde os anos 1980, os programas de coleta seletiva ainda são raros no país, e, quando existem, muitos são incompletos e ineficazes. Segundo Instituto de Pesquisa Econômica Aplicada (Ipea, 2011), apenas 2,4\% de todo o serviço de coleta de resíduos sólidos urbanos no Brasil é realizado de forma seletiva, sendo todo o restante realizado como coleta regular, sem a separação na fonte geradora, dificultando a reciclagem de parte desses materiais

Tal fato limita fortemente o reaproveitamento econômico desses resíduos, uma vez que, pensando em termos de cadeia de produção de valor, a reciclagem pode ser entendida como uma atividade componente de um sistema de gestão integrada que remete às etapas de recuperação de resíduos urbanos e sua utilização como matéria-prima secundária. Nesse sentido, o processo de recuperação da matériaprima é definido por todo o conjunto de ações envolvendo a coleta seletiva e triagem dos resíduos, sua limpeza e prensagem ou enfardamento, a logística de transporte, deixando-o pronto para ser transformado em matéria-prima secundária. A esta última etapa fica reservado o termo "reciclagem" propriamente dito. Os materiais são separados de acordo com suas características físicas (papéis, plásticos, metais ferrosos, alumínio e vidros), tendo cada material um determinado valor, processo próprio de transformação ou reciclagem e uma demanda específica. Todas essas colocações demonstram que a estrutura organizacional da cadeia da reciclagem é bem complexa, o que torna extremamente difícil o estabelecimento de uma política ou estratégia nacional para o fortalecimento de seu maior aproveitamento industrial e para a coordenação de programas de coleta seletiva.

Os principais atores envolvidos nessa cadeia geral de valor se inserem em um arranjo rigidamente hierarquizado, no qual um reduzido número de indústrias recicladoras (incluindo o pré-beneficiamento, o beneficiamento e a transformação dos recicláveis em novos produtos) ocupa o "topo da pirâmide", atuando com poder de monopsônio. Abaixo delas encontram-se os agentes “intermediários”, que geralmente organizam toda a infraestrutura necessária (balança, prensa, triturador, caminhões, galpão e capital financeiro) para a compra dos materiais que são separados e oferecidos em grandes volumes às indústrias recicladoras (SANTOS et al., 2011).

Já na chamada "base da pirâmide" encontram-se milhares de pessoas que trabalham diretamente na coleta, separação e triagem dos resíduos. Embora seja difícil definir o número exato de pessoas envolvidas nessa atividade, os dados do censo populacional de 2010 apontam que cerca de 400 mil pessoas, em todo o 
Brasil, responderam ter como atividade remunerada principal a coleta de materiais recicláveis, sendo dois terços do sexo masculino (SILVA, GOES, ALVAREZ, 2013; DAGNINO, JOHANSEN, 2017). O trabalho realizado por eles consiste em coletar, separar, transportar, acondicionar e, às vezes, beneficiar o material dos resíduos sólidos utilizados que tem valor de mercado e poderá ser vendido para reutilização ou reciclagem. Ou seja, através de sua atividade cotidiana, esses trabalhadores transformam o resíduo sólido em mercadoria novamente. É por esse processo, portanto, que ocorre a ressignificação do "lixo" (algo considerado inútil a princípio) em mercadoria com valor de uso e valor de troca (MAGALHÃES, 2012).

Além de terem pouco controle sobre a estrutura de governança da cadeia produtiva dos recicláveis, a renda dos catadores sofre fortes variações de acordo com o movimento do dólar e dos preços internacionais das commodities relacionadas aos principais produtos que eles coletam, tais como petróleo (plástico), minério de ferro, alumínio, celulose, entre outros. A proximidade física da indústria compradora também influencia no nível de preços auferido pelos catadores. Entretanto, além de poucas, essas indústrias são concentradas em regiões de maior desenvolvimento econômico, o que interfere na possibilidade de comercialização, por parte de catadores ou mesmo intermediários pouco organizados, pois há a exigência de altos custos de transporte e armazenamento. Por isso, quanto maior a demanda na região por determinado resíduo, e quanto mais próximos os empreendimentos estiverem das unidades compradoras, melhores serão as possibilidades de comercialização e, por conseguinte, melhores preços podem ser alcançados pelos produtos.

Contudo, é importante ressaltar que a categoria social dos catadores não constitui um conjunto populacional homogêneo. Ela é marcada por uma forte diversidade entre seus integrantes, em termos de trajetória de vida. Muitos deles exercem a atividade em tempo integral por muitos anos, desde a infância, e, em algumas famílias, essa atividade passa a ser seguida pelos filhos, na grande maioria das vezes por falta de outra opção. Outros a iniciam por questões contingenciais, como a perda do emprego, por exemplo. Existem também aqueles que intercalam a catação com outros trabalhos, ou então trabalham como catadores nos intervalos entre um e outro emprego eventual. Em termos de local de trabalho, há aqueles que trabalham em rotas específicas de coleta na cidade, passando em áreas residenciais e em empresas, assim como há aqueles que trabalham em lixões ou aterros sanitários, onde são despejadas toneladas de lixo todos os dias. Há também aqueles que são empregados e trabalham em locais fixos de catação, separação e classificação do material reciclável. Cada uma dessas situações contêm particularidades que determinam o perfil socioeconômico, o nível de carência e até mesmo o nível de integração social dessas famílias, o que confere a esse fenômeno social uma enorme complexidade (SILVA; GOES; ALVAREZ, 2013).

Apesar de toda essa diversidade, em termos de identidade laboral, é possível dizer que, em suma, o trabalho é realizado a partir de relações informais, ou seja, não registradas formalmente com base na legislação trabalhista vigente. Além de não permitir aos catadores o acesso a uma série de direitos trabalhistas, a informalidade dificulta seu reconhecimento pelos órgãos da administração pública e instituições 
de pesquisas. O problema da informalidade é ainda mais preocupante quando se considera as condições de risco para a saúde desses trabalhadores, pois os deixam desguarnecidos de qualquer seguro social para o caso de algum acidente ou doença que lhes impossibilite de trabalhar por um período.

Mesmo compondo a parte mais frágil da cadeia de valor da reciclagem, os catadores são os atores-chave em todo o processo de produção de valor nesse setor, uma vez que é baixa a participação de empresas privadas na coleta (GUTIERREZ; ZANIN, 2011). Estima-se que eles são responsáveis por cerca de $90 \%$ de todo o material que chega a ser reciclado no Brasil (INSTITUTO DE PESQUISA ECONÔMICA APLICADA, 2011). O reconhecimento desse papel possibilitou aos catadores de material reciclável no Brasil iniciar, nos últimos anos, uma trajetória de mobilização coletiva. Um marco histórico importante foi a realização do $1^{\circ}$ Congresso Nacional dos Catadores de Papel, ocorrido em Belo Horizonte, em 1999, onde foi debatida a ideia de se criar um movimento nacional de catadores. Como resultado, foi criado oficialmente, em junho de 2001, o Movimento Nacional dos Catadores de Materiais Recicláveis (MNCR), durante o I Congresso Nacional de Catadores de Materiais Recicláveis, realizado em Brasília.

Uma das primeiras conquistas do MNCR foi assinatura da Portaria $n^{\circ}$ 397/2002 do Ministério do Trabalho. Por meio dela, foi inserida na Classificação Brasileira de Ocupações (CBO), que é o documento que reconhece, nomeia e codifica as características das ocupações no mercado de trabalho brasileiro, a profissão de "catador de material reciclável", com o código 5192-05. A partir dessa nova $\mathrm{CBO}$, os catadores passaram a ser oficialmente reconhecidos como uma categoria profissional (GUTIERREZ; ZANIN, 2011).

Atualmente, o MNCR é reconhecido como a principal organização nacional de defesa dos interesses dos catadores do mundo, e, ao longo dos anos, conseguiu estender suas articulações para outros países. Em 2003, ocorreu o I Congresso Latinoamericano de Catadores de Material Reciclável, com a divulgação da Carta de Caxias do Sul, de grande importância para estreitar o diálogo e unificar a pauta de reivindicações com catadores e organizações da América Latina, em especial no Mercosul. O II Congresso Latinoamericano de Catadores aconteceu em 2005, quando o movimento assumiu algumas orientações direcionadas ao fortalecimento de associações e cooperativas, assim como das políticas públicas e normas relacionadas aos catadores. Em 2008, aconteceu o III Congresso Latinoamericano de Catadores, na Colômbia, no qual foi proclamada a Carta de Bogotá, um documento que estimula o compromisso das organizações participantes visando a mobilização mundial do reconhecimento da profissão de catador de material reciclável (SILVA; GOES; ALVAREZ, 2013).

À medida que os catadores foram avançando, em termos de organização e articulação coletiva, passaram a ter, como segmento socialmente reconhecido, um maior respaldo para negociar as questões inerentes a sua cidadania e atividade profissional. Assim, o Estado brasileiro, em suas distintas esferas administrativas, tem instituído, nos últimos anos, uma série de atos normativos na forma de leis, regulamentos, decretos, portarias e normas sobre a gestão dos resíduos sólidos, com destaque para a Lei $n^{\circ} 12.305 / 2010$, que estabeleceu a Política Nacional de Resíduos 
Sólidos (PNRS), abrindo um novo horizonte de atuação para os grupos produtivos de catadores em todo o país ${ }^{1}$.

Paralelamente a esse esforço coletivo de articulação e representação política da categoria, houve também avanços em termos de organização coletiva do trabalho em empreendimentos econômicos. Nessa questão, o MNCR se aproximou, desde seu início, do movimento de economia solidária no Brasil, que defendia as diretrizes do trabalho associado e da autogestão. As próximas seções abordarão diretamente essa relação.

\section{Economia solidária e trabalho associado:}

características gerais e particularidades para o setor de reciclagem

O debate em torno da importância do trabalho coletivo e da autogestão em unidades produtivas em plena era de acirramento da competição capitalista globalizada tem ganhado novas vertentes analíticas não apenas no Brasil, mas em diversos países da América Latina e também na Europa. Uma dessas vertentes congrega um considerável conjunto de pesquisadores, trabalhando em rede ou individualmente, em suas instituições, envolvidos com a temática da chamada "economia solidária". Trata-se de uma nova perspectiva política e acadêmica que aborda, sob diferentes prismas teóricos e empíricos, a mobilização popular em torno do apoio à formação de grupos produtivos associativos, de caráter suprafamiliar (LAVILLE, 2009; SILVA, 2017b).

De maneira geral, a economia solidária pode ser vislumbrada como o conjunto das atividades, com diversos formatos organizacionais, que contribuem para a democratização econômica a partir do engajamento coletivo de trabalhadores. Sua ideia traz consigo princípios que perpassam, em diferentes graus, a busca pela satisfação das necessidades humanas, a igualdade de oportunidades, a preservação do meio ambiente e a luta por justiça social e garantia dos direitos fundamentais dos cidadãos. Esses grupos, organizados nas mais distintas atividades econômicas, são conhecidos comumente, no Brasil, como "empreendimentos de economia solidária” (EES), que constituem sua célula básica de representação na dinâmica econômica real (SILVA, NAGEM, 2012; GAIGER, 2014; SILVA, CARNEIRO, 2016; SILVA, 2017a). Seus princípios básicos de distinção em relação às demais empresas capitalistas, apontados pela maioria dos autores que tratam o tema, são: posse coletiva dos meios de produção pelas próprias pessoas que os utilizam para produzir; gestão democrática por participação direta ou, no caso dos empreendimentos maiores, por representação; repartição da receita líquida entre os associados; destinação do excedente anual segundo critérios acertados entre todos os cooperadores (SINGER, 2002; GAIGER, 2013).

O caráter coletivo desses empreendimentos recebe um destaque especial na análise de Demoustier (2006). Para a autora, um empreendimento do 
campo da economia solidária não se reduz a uma soma de empreendedores individuais, pois seus integrantes constroem sinergias à medida que conjugam suas motivações e seus recursos. Essa conjugação permite uma acumulação de competências interna (por meio do aprendizado mútuo) e externas (por meio da constituição de diferentes tipos de articulações), que vão gerar a "combinação produtiva" necessária e essencial para a viabilidade do projeto. Com isso, o princípio da "dupla qualidade" de seus membros (de serem ao mesmo tempo sócios e trabalhadores ou usuários do empreendimento) configura-se como a base do agrupamento de um empreendimento coletivo, "pois ele vincula o poder de decisão não à propriedade do capital e sim à participação na realização da atividade" (DEMOUSTIER, 2006, p. 104). Por outro lado, Demoustier (2006) ressalta que os empreendimentos coletivos (dada a coexistência de motivações e identidades diversas) enfrentam o desafio de combinar e articular difíceis lógicas econômicas, sociais, culturais e políticas, resultando em uma difícil missão de "conciliar a autonomia individual e o engajamento coletivo" em torno de "identidades sociais" e compromissos comuns.

No que diz respeito à prática concreta da autogestão nos EES, a constituição de mecanismos internos que garantem e incentivem os associados a participarem diretamente das decisões cotidianas nos empreendimentos surge como um dos grandes desafios, mesmo sendo um dos aspectos centrais de distinção das práticas caracterizadas como de economia solidária. Isto porque a própria ideia de que os trabalhadores são ao mesmo tempo sócios gera responsabilidades diferenciadas em comparação com uma empresa comum, não sendo algo tão simples de ser assimilado internamente pelos associados. Em grupos menores, a circulação de informações é maior e os custos da participação são menores; mas, em empreendimentos com um maior contingente de sócios, há uma necessidade de se estabelecer estratégias diferenciadas para garantir o exercício da gestão democrática.

Nesse contexto, o setor da reciclagem apresenta um campo de análise bastante particular e desafiador, em termos de mobilização coletiva dos atores para a geração de renda, dadas as características econômicas intrínsecas à atividade e também a realidade social que define a identidade, na maioria das vezes marginalizada, de sua força de trabalho. Embora a atuação em empreendimentos associativos seja um fenômeno relativamente recente para a categoria dos catadores, ela pode ser indicada como o 'primeiro passo' para o rompimento com a forma individualizada de trabalho nas ruas e em depósitos de lixo. Através deles, o material coletado pode ser negociado em maior quantidade e melhor qualidade, obtendo melhores valores para os produtos, inclusive com a possibilidade de venda direta às empresas, sem passar pelos intermediários (FÉ, FARIA, 2011; PINHEL, 2013; ARIOLI, 2016).

Além da finalidade econômica, os empreendimentos coletivos de catadores também atuam como veículos de representação de seus associados junto ao poder público, dando-lhes um peso maior para reivindicar, entre outras coisas, a cessão de espaços adequados para armazenar e separar o material recolhido, além de programas de financiamento para seu processamento e agregação de valor. Há ainda 
relatos de pessoas que reconhecem no trabalho organizado um espaço de segurança em relação ao trabalho individualizado no lixão ou nas ruas (CHERFEM, 2016). Por isso, as cooperativas e associações são vistas como instrumentos de inserção social, por proporcionarem uma série de vantagens e melhores condições de trabalho a esses indivíduos.

No entanto, é necessário enfatizar que a gestão de empreendimentos coletivos - como no caso das cooperativas - não é algo trivial, uma vez que tais empreendimentos apresentam considerável complexidade em termos de estrutura e funcionamento, dada a diversidade de motivações, contextos e dinâmicas operacionais que envolve as cooperativas. Por isso, são exigidos conhecimentos especializados em diferentes áreas para sua consolidação, tanto em termos de atividades práticas do empreendimento quanto em funções burocráticas e administrativas. No caso de uma cooperativa de catadores, são diversas as etapas básicas de funcionamento que precisam ser controladas, tais como o transporte, a triagem, o beneficiamento e a comercialização dos materiais, além do apoio técnico para a qualificação profissional e a gestão interna de conflitos. Ademais, as dificuldades gerenciais podem incorrer na própria descaracterização do empreendimento como grupo autogestionário (LIMA, 2004; LEITE, 2009; ZANIN, GUTIERREZ, 2011). Para auxiliar no enfrentamento dessas questões, existe um conjunto de entidades da sociedade civil e algumas governamentais que trabalham diretamente com grupos de trabalhadores em empreendimentos de economia solidária para o assessoramento de sua organização socioprodutiva, nas mais diversas demandas apresentadas por eles. Essas entidades têm distintos vínculos institucionais, que vão desde os movimentos sociais e sindicais até o poder público, igrejas, entre outros (SILVA, 2016).

A primeira cooperativa formada por catadores de que se tem registro no Brasil é a Cooperativa dos Catadores de Papel, Aparas e Materiais Reaproveitáveis (Coopamare), fundada em 1989, no município de São Paulo, contando inicialmente com vinte catadores associados. Em 1990, foi constituída a Associação dos Catadores de Papel, Papelão e Material Reaproveitável de Belo Horizonte (Asmare), com o apoio da Pastoral de Rua da Arquidiocese de Belo Horizonte. Essa é uma das iniciativas de economia solidária no campo da reciclagem mais conhecida e estudada no país atualmente. A Asmare foi formada inicialmente com dez associados, contando atualmente com mais de 300. Em 1993, a Asmare passou a integrar, como parceira, o Projeto de Coleta Seletiva do município, representando um dos casos pioneiros de parceria entre empreendimento de catadores e poder público (MAGALHÃES, 2012).

Com o objetivo de expandir sua capacidade de comercialização e troca de experiências, a Asmare, juntamente com outras nove associações e cooperativas da Região Metropolitana de Belo Horizonte (RMBH), organizou-se para constituir, em 2006, a Rede de Economia Popular e Solidária Cataunidos, primeira cooperativa de segundo grau formada por catadores, no Brasil. A iniciativa de formação de redes desse tipo, entre empreendimentos, constitui uma inovação organizacional no setor de recicláveis, sobretudo por implicar uma nova dimensão estratégica para a atividade de catação e estratégias de comercialização, conferindo 
identidade e organicidade aos grupos. Além da Cataunidos, outros exemplos de redes foram constituídos no Brasil, evidenciando a possibilidade de ganhos de escala, difusão de conhecimento e compartilhamento de práticas de gestão entre os empreendimentos.

A literatura especializada aponta que, para alcançar bons níveis de eficiência, os empreendimentos de catadores necessitam de um conjunto de infraestrutura e equipamentos que são fundamentais para o exercício de sua atividade, tais como: sede própria; barracão com espaço adequado para triagem e armazenamento dos resíduos; caminhão para a coleta seletiva e transporte dos resíduos; telefone; computadores com acesso à internet; mesas e bags para triagem; prensas para comprimir os resíduos; carrinhos manuais para transporte; entre outros. Para além da estrutura física, outro ponto importante considerado por alguns autores diz respeito ao acesso a tecnologias adequadas à natureza associativa de sua organização. (DAGNINO, 2008; PEPINELLI, 2011).

No entanto, um fator característico importante sobre os empreendimentos de economia solidária no campo da reciclagem refere-se à diversidade da estrutura operacional que apresentam. Segundo Pepinelli (2011, p. 145), eles interagem de maneira diferenciada na cadeia produtiva da reciclagem "conforme o tipo de resíduo comercializado, as tecnologias utilizadas e as parcerias estabelecidas". Essa heterogeneidade estrutural - que também é característica geral da economia solidária no Brasil (SILVA, 2017a) - impacta diretamente em sua eficiência econômica. A seção seguinte trata mais diretamente dessas questões.

\section{Panorama dos empreendimentos coletivos de reciclagem}

\section{Dimensões estruturais de empreendimentos coletivos de catadores}

Existem poucas pesquisas aprofundadas que possibilitem a realização de diagnósticos mais precisos sobre a realidade socioeconômica dos empreendimentos econômicos solidários (EES), no campo da reciclagem, no Brasil. Ainda assim, alguns esforços recentes de pesquisadores, em parceria com órgãos de governo, e de representantes do movimento de economia solidária, desenvolveram trabalhos importantes que permitem a definição de caracterizações gerais relativas a esse universo laboral no país. Dois em especial serão utilizados nesta seção.

No primeiro, Damásio (2010) analisou uma série de variáveis socioeconômicas em um conjunto de 83 empreendimentos coletivos de reciclagem em todas as grandes regiões brasileiras, à exceção da região Norte, entre os anos 2006 e 2009. O autor diferenciou as unidades produtivas por graus de eficiência identificados na pesquisa, conforme listado a seguir no Quadro 1. 
Quadro 1 - Graus de eficiência das cooperativas de catadores

\section{Grau de} Eficiência

\section{Características}

Produtividade média

Alta Grupos formalmente organizados em associações eficiência ou cooperativas, com prensas, balanças, carrinhos e galpões próprios, com capacidade de ampliar suas estruturas físicas. Detêm um conjunto apreciavelmente elevado de conhecimentos Acima de $1.800 \mathrm{Kg}$ por adquiridos, passíveis de difusão e verticalização da catador/mês. produção.

Média Grupos formalmente organizados em associações eficiência ou cooperativas, contando com alguns equipamentos e/ou galpões, porém precisando de apoio financeiro para a aquisição de outros. Detêm algum conhecimento adquirido.

Entre $1.100 \mathrm{e}$ $1.800 \mathrm{Kg}$ por catador/mês.

Baixa Grupos ainda em organização, contando com eficiência poucos equipamentos, mas precisando de apoio financeiro para a aquisição de quase todos os Entre 550 e equipamentos necessários, além de galpões próprios. Detêm pouco capital e necessitam de $1.100 \mathrm{Kg}$ por forte apoio para treinamento e aprendizado de catador/mês. conhecimentos adicionais.

Baixíssima Grupos desorganizados - em ruas ou lixões eficiência -, sem possuírem quaisquer equipamentos, e frequentemente trabalhando em condições de extrema precariedade para atravessadores. Necessitam de apoio financeiro para a montagem completa da infraestrutura de edificações e de Abaixo de $550 \mathrm{Kg}$ por catador/mês. equipamentos, para o aperfeiçoamento técnico e na organização de suas cooperativas.

Fonte: Damásio (2010).

A divisão das unidades produtivas de catadores em agrupamentos por níveis de eficiência permite um olhar sobre o conjunto das organizações, enfocando seu desempenho e suas necessidades de infraestrutura e conhecimento. Com base nessas especificações, Damásio (2010) chegou aos seguintes números, conforme mostrados 
na Tabela 1. Tanto entre o número de organizações quanto de catadores, detectou-se que cerca de $60 \%$ estão em situação de baixa ou baixíssima eficiência.

Tabela 1 - Organizações coletivas e catadores por grau de eficiência

\begin{tabular}{lrrrrr}
\hline Graus de Eficiência & $\begin{array}{r}\text { No de } \\
\text { Organizações }\end{array}$ & \% & Catadores & \% & $\begin{array}{r}\text { Média (Kg/ } \\
\text { Catador) }\end{array}$ \\
\hline Alta eficiência & 12 & 14 & 627 & 16 & $2.292,9$ \\
Média eficiência & 22 & 27 & 911 & 24 & $1.480,7$ \\
Baixa eficiência & 29 & 35 & 1.673 & 43 & 913,0 \\
Baixíssima eficiência & 20 & 24 & 635 & 17 & 224,9 \\
\hline TOTAL & $\mathbf{8 3}$ & $\mathbf{1 0 0}$ & $\mathbf{3 . 8 4 6}$ & $\mathbf{1 0 0}$ & \\
\hline
\end{tabular}

Fonte: Adaptado de Damásio (2010).

Esses números revelam a extrema disparidade entre os empreendimentos investigados. As cooperativas de 'alta eficiência' apresentam produtividade física média dez vezes superior à média das cooperativas de 'baixíssima eficiência'. Tal heterogeneidade pode ser identificada como sendo função de uma série de fatores, tais como: distribuição desigual na alocação de máquinas e equipamentos; acesso a locais onde são depositados os resíduos; eficiência da coleta e triagem; formas de organização do trabalho; área geográfica de atuação; acondicionamento correto dos materiais, preservando-os de contaminantes e da umidade; obediência aos padrões exigidos em cada indústria; custos logísticos, entre outros.

Por outro lado, é oportuno também deixar claro que a eficiência física e a eficiência econômica dos empreendimentos estão ligadas entre si pela relação entre quantidade coletada e preços de mercado. No caso específico da "produtividade física”, não há uma dependência direta dos preços relativos dos materiais recicláveis, nem das condições objetivas de inserção das cooperativas nas cadeias de comercialização. Isso implica que as produtividades físicas não são afetadas por bruscas variações de preços, mesmo em períodos de crise, embora tais fatores possam causar disparidades significativas em seus níveis de eficiência econômica.

A segunda fonte de informações para a análise aqui pretendida refere-se ao Sistema de Informações de Economia Solidária (Sies), coordenado pela Secretaria Nacional de Economia Solidária (Senaes), órgão ligado ao Ministério do Trabalho e Emprego. O Sies buscou realizar um levantamento nacional dos chamados empreendimentos de economia solidária (EES) para verificar informações 
sobre distintas dimensões de seu funcionamento (NAGEM, SILVA, 2013; SILVA, CARNEIRO, 2016; SILVA, 2017a). A pesquisa de campo foi realizada entre 2010 e 2013, envolvendo não apenas cooperativas e associações já regularizadas, mas também grupos informais em vias de regularização. Ao todo, foram entrevistados representantes de 19.708 EES, nas mais diversas atividades econômicas. Desse total, foi possível identificar que 591 têm como atividade principal a reciclagem de resíduos sólidos. Por isso, as análises aqui desenvolvidas recaem sobre esse subtotal.

O empreendimento mais antigo desse total é de 1981, mas a maior parte deles foi constituída recentemente. Mais da metade $(56,5 \%)$ surgiu a partir de 2005. Em termos de divisão regional, a região Sudeste obteve o maior número de EES entrevistados (324 ou 54,8\% do total), seguida pela região Sul (154 ou 26,1\%). Nordeste (54), Centro-oeste (31) e Norte (28) responderam conjuntamente por menos de $20 \%$ do total.

$\mathrm{Na}$ dimensão administrativa desses empreendimentos, destacam-se aqui as informações sobre a forma de organização e suas peculiaridades em termos de quadro social. A maior parte dos grupos encontra-se ainda na informalidade $(40,3 \%)$, seguida pela forma de associação (31,3\%) e de cooperativa $(28,3 \%)$. Apenas um empreendimento mapeado está organizado sob a forma de sociedade mercantil. Importante ressaltar, nesse caso, que a proporção de cooperativas entre os empreendimentos de catadores é cerca de três vezes a proporção geral do universo de EES mapeados. Uma explicação possível para esse resultado seria os diversos programas públicos de apoio à formalização de cooperativas entre os catadores para a participação em programas de coleta seletiva e outras políticas de apoio ao setor.

A grande maioria destes empreendimentos de catadores mapeados pelo Sies é composta por número reduzido de associados: 59,8\% deles têm até vinte sócios; $31,0 \%$ entre 21 e 50; 6,0\% entre 51 e 100; e apenas 3,2\% têm mais de 100 pessoas associadas. A média indicou em torno de 30 trabalhadores associados por empreendimento. A Tabela 2, a seguir, mostra que os grupos informais tendem a ter menor número de sócios enquanto, proporcionalmente, as cooperativas apresentam quadro social mais elevado. Digna de nota é a predominância de mulheres em tais empreendimentos (59,9\% do total de 15.732 associados). Interessante notar essa predominância feminina, já que os dados do censo populacional demonstram que somente um terço das pessoas que declararam trabalhar como catadores são mulheres (SILVA; GOES; ALVAREZ, 2013). 
Tabela 2 - Número de sócios participantes por tipo de organização

\begin{tabular}{|c|c|c|c|c|c|}
\hline \multirow[b]{2}{*}{ Tipo de organização } & \multicolumn{4}{|c|}{ Número total de sócios } & \multirow[b]{2}{*}{ Total } \\
\hline & $\begin{array}{l}\text { Até } 20 \\
\text { sócios }\end{array}$ & $\begin{array}{l}\text { Entre } 21 \text { e } \\
50 \text { sócios }\end{array}$ & $\begin{array}{l}\text { Entre } 51 \text { e } \\
100 \text { sócios }\end{array}$ & $\begin{array}{r}\text { Mais de } \\
100 \text { sócios }\end{array}$ & \\
\hline Associação & 101 & 60 & 12 & 11 & 184 \\
\hline Cooperativa & 44 & 96 & 19 & 7 & 166 \\
\hline Grupo informal & 150 & 82 & 4 & 1 & 237 \\
\hline Sociedade mercantil & 0 & 1 & 0 & 0 & 1 \\
\hline Total & 295 & 239 & 35 & 19 & 588 \\
\hline
\end{tabular}

Fonte: Banco de dados do Sies. Elaboração própria.

Nota ${ }^{1}$ : Três EES não responderam quanto ao número de sócios.

Em termos de participação nas decisões internas, os instrumentos mais comuns citados pelos representantes são a assembleia geral ou a reunião coletiva. De acordo com os dados, 61,6\% afirmaram existir uma participação massiva dos associados nessas atividades realizadas no ano anterior. Outros 34,0\% alegaram que mais da metade comparece. Já em termos de periodicidade, $61,4 \%$ dos EES de reciclagem informaram realizar ao menos uma assembleia ou reunião coletiva mensal, e apenas $1,9 \%$ do total disse não ter realizado esse tipo de atividade no ano anterior à pesquisa.

$\mathrm{Na}$ dimensão econômica, foram analisadas questões de comercialização, de captação de recursos, acesso a crédito e investimentos feitos, além do nível de renda possibilitado pelo trabalho associado. A maior parte dos EES consultados respondeu dizendo enfrentar dificuldades na comercialização de produtos ou serviços $(56,7 \%)$, sendo a principal dificuldade apontada os preços praticados, considerados inadequados $(15,1 \%)$, seguida pelo fato de os compradores só adquirirem grandes quantidades (12,7\%), e o problema da ação dos atravessadores (11,8\%). Outras dificuldades apontadas foram: falta de capital de giro; excesso de burocratização para a formalização das cooperativas; insuficiência e rotatividade de associados.

A atividade profissional desempenhada nos EES de reciclagem é citada como a principal fonte de renda dos sócios em $84,1 \%$ dos entrevistados, os demais afirmaram ser a atividade uma complementação de rendimentos recebidos em outras atividades econômicas, ou de recursos recebidos por programas sociais e/ou 
previdenciários. Esses dados apontam para a importância desses empreendimentos na geração de trabalho e renda para um contingente considerável de pessoas que, por diferentes motivos, escolhem essa atividade para sobreviver.

Em termos gerais, os investimentos iniciais para a constituição da maior parte desses EES vêm de recursos próprios dos sócios (caso identificado em 33,9\% dos entrevistados), principalmente no caso de empreendimentos informais, pouco estruturados. Nos outros casos, os recursos foram oriundos de fundos públicos não reembolsáveis, doação de pessoas físicas ou empresas, doação de organismos internacionais ou ONGs e, em menor parte, via empréstimos ou financiamentos (apenas 2,7\%). Tal informação ilustra a dificuldade que esses EES têm em obter crédito para suas atividades, muito em função da informalidade e da incapacidade de apresentarem garantias econômicas para linhas de financiamento bancário.

Por esse motivo, $82 \%$ não buscaram crédito para suas atividades nos doze meses anteriores à pesquisa. Entre os demais, 10,2\% buscaram, mas não obtiveram (Tabela 3). Apenas 7,8\% obtiveram algum tipo de crédito ou financiamento. Apesar disso, mais da metade dos EES de reciclagem (53,3\%) alegou necessitar de crédito, sobretudo para investimentos diversos nos empreendimentos. Em virtude dessa dificuldade em conseguir linhas de crédito, pouco mais da metade dos EES $(50,6 \%)$ conseguiu realizar algum tipo de investimento nos doze meses anteriores à pesquisa. As principais destinações para os investimentos foram: aquisição ou renovação de equipamentos (46,3\%); melhorias de infraestrutura física $(30,3 \%)$; capacitação de mão de obra (12,8\%); e comunicação $(4,8 \%)$.

Tabela 3 - Dificuldades para obtenção de crédito ou financiamento

\begin{tabular}{lrr}
\hline \multirow{2}{*}{ Dificuldades } & \multicolumn{2}{c}{ Respostas $^{\mathbf{1}}$} \\
& Qtde & \% \\
\hline Não possui documentação exigida & 82 & 15,9 \\
Taxa de juros elevada ou incompatível & 88 & 17,1 \\
Prazos de carência inadequados & 37 & 7,2 \\
Falta aval ou garantia & 71 & 13,8 \\
Falta apoio para elaborar projetos & 50 & 9,7 \\
Burocracia & 105 & 20,3 \\
Falta linha de crédito & 66 & 12,8 \\
Outra & 17 & 3,3 \\
\hline Total & $\mathbf{6 9 4}$ & $\mathbf{1 0 0 , 0}$ \\
\hline
\end{tabular}

Fonte: Banco de dados do Sies. Elaboração própria.

Nota: ${ }^{1}$ Resposta múltipla, com 210 respondentes. 
Em termos de assessoria, assistência ou capacitação, a maior parte dos EES $(79,9 \%)$ afirmou ter recebido algum apoio ao longo dos doze meses anteriores (Tabela 4). Entre as entidades de apoio apontadas, as principais foram: governo municipal; Organizações não Governamentais e Organizações da Sociedade Civil de Interesse Público (Oscips); organizações do chamado Sistema $\mathrm{S}$ - Serviço Brasileiro de Apoio às Micro e Pequenas Empresas (Sebrae), Serviço Nacional de Aprendizagem do Cooperativismo (Sescoop) e Serviço Nacional de Aprendizagem Rural (Senar); e universidades - com destaque para a atuação das incubadoras tecnológicas de cooperativas populares (ITCPs).

Tabela 4 - Tipo de apoio recebido pelo empreendimento

Tipo de apoio

Respostas $^{1}$

\begin{tabular}{lcc} 
& Qtde & (\%) \\
\hline Assistência técnica e/ou gerencial & 241 & 13,1 \\
Qualificação profissional, técnica e gerencial & 270 & 14,7 \\
Formação sócio-política (autogestão, cooperativismo, & 319 & 17,4 \\
economia solidária) & & \\
Assistência jurídica & 170 & 9,2 \\
Assessoria em marketing e na comercialização de produtos e & 123 & 6,7 \\
serviços & 194 & 10,6 \\
Diagnóstico, planejamento e análise de viabilidade econômica & 235 & 12,8 \\
Assessoria na constituição, na formalização ou no registro & 201 & 10,9 \\
Elaboração de projetos & 85 & 4,6 \\
Incubação para a formalização & $\mathbf{1 8 3 8}$ & $\mathbf{1 0 0 , 0}$ \\
\hline Total & &
\end{tabular}

Fonte: Banco de dados do Sies. Elaboração própria.

Nota: ${ }^{1}$ Resposta múltipla, com 472 respondentes.

Por fim, os dados do Sies também apresentam algumas informações referentes à dimensão sociopolítica dos empreendimentos, abordando aspectos de suas articulações, seja no plano local, seja no nacional. Em termos de articulação econômica, 80,5\% deles afirmaram não participar de nenhuma rede de empreendimentos (rede de produção, comercialização, consumo ou crédito). Dos 
$18,5 \%$ que afirmaram participar de alguma, as redes de comercialização foram as mais citadas. Quanto à articulação política, 54,7\% afirmaram também não participar de nenhum fórum ou rede de articulação ou representação, o que demonstra uma fragilidade relacional e representativa dos empreendimentos no território nacional, em que pese o avanço em termos de representação política desse segmento no país.

\section{Apontamentos gerais sobre a organização coletiva dos catadores}

As informações debatidas até aqui demonstram que o trabalho em empreendimentos coletivos tem algumas características que favorecem o desempenho dos catadores. Isso porque, no trabalho individual, o que se observa é a concentração das funções na figura do próprio catador, responsável pela coleta, separação, armazenamento e comercialização. Com isso, eles ficam mais vulneráveis à ação de intermediários comerciais, ou “atravessadores”. Esses agentes, ao controlarem a compra, estocagem e encaminhamento do material coletado para as indústrias de reciclagem, têm o poder de determinar, por imposição, o valor a ser pago e as condições exigidas pelo material coletado, apropriando-se assim de grande parte do excedente produzido na fase da coleta pelos catadores individuais. Além disso, o trabalho coletivo em cooperativas permite melhores condições para viabilizar o investimento em infraestrutura (como a construção de galpões) e maquinários (prensas, veículos) para melhorar as condições de trabalho, o que, individualmente, não seria possível. No entanto, ainda assim, há um número bem superior de trabalhadores individuais no setor da reciclagem ${ }^{2}$.

Vários motivos podem ser creditados a essa baixa adesão ao trabalho coletivo, dentre os quais podem ser citados: i) muitos catadores preferem atuar sozinhos em nome de uma suposta - e por que não dizer, ilusória - autonomia na gestão de seu tempo e do resultado de seu trabalho; ii) há uma desinformação muito grande quanto às exigências para constituição de cooperativas e associações; iii) o processo de criação desses empreendimentos exige conhecimento técnico especializado, tanto na sua constituição quanto na sua gestão, o que requer dos catadores o estabelecimento de parcerias que lhes garantam o assessoramento técnico necessário; iv) muitos catadores enxergam as cooperativas como um agente externo e não como organizações formadas e geridas por eles próprios, que são os verdadeiros donos do empreendimento.

Esse conjunto de fatores elencados é relevante para ressaltar que a gestão eficaz de um empreendimento coletivo exige de todos os associados o pleno entendimento da estrutura de produção, dos deveres e direitos de cada um no funcionamento da cooperativa. Porém, alcançar esse entendimento não é uma tarefa trivial, visto exigir a construção de canais de confiança e reciprocidade entre os participantes, construção essa que requer um longo processo de aprendizagem e prática da cooperação.

2 As estimativas apontam que o percentual de trabalhadores ligados a cooperativas e associações, nesse setor, gira em torno de apenas 10\% (SILVA; GOES; ALVAREZ, 2013). 
É justamente nessa questão - envolvendo uma barreira que ao mesmo tempo é cultural e social - que reside o grande desafio para o desenvolvimento dos princípios da economia solidária entre os catadores de material reciclável. Seus integrantes são, de maneira geral, pessoas inseridas em jornadas informais de trabalho, com baixa escolaridade e convivem em um ambiente de múltiplas precariedades. Dispõem apenas da remuneração advinda de seu próprio trabalho para a manutenção familiar. Tais dificuldades os levam a buscar soluções imediatas de resolução de suas carências individuais e familiares.

Há também a questão relativa à alta rotatividade de seus integrantes. Como muitos deles estão no limiar do mercado de trabalho, é comum alguns abandonarem a atividade com a catação quando se inserem em algum emprego formal e retornarem ao empreendimento quando esse vínculo termina. Por isso, torna-se fundamental observar que a condição social dos catadores implica a emergência da obtenção de renda para as famílias envolvidas.

Aqueles que conseguem superar essas dificuldades iniciais, arcando com os "custos do aprendizado" durante a formação do empreendimento, muitas vezes com o apoio técnico e financeiro de entidades de fomento ou do poder público, tendem a conseguir uma inserção mais vantajosa na cadeia de valor da reciclagem. Ao trabalharem em conjunto, ou em rede, os catadores alcançam maior poder de barganha com relação à comercialização de seu material.

Outro fator que pesa positivamente para o trabalho em conjunto diz respeito à melhor capacidade de planejamento e divisão de trabalho, propiciando uma racionalização da força de trabalho disponível para as atividades, de acordo com as condições físicas e de tempo de cada indivíduo associado, além de melhorias nas próprias condições de trabalho, com a definição de jornada regular, adoção de equipamentos de proteção individual e de condições sanitárias mais adequadas ao desempenho de suas atividades. Com isso, como destacado por Damásio (2010), pode-se obter maior produtividade e eficiência econômica no empreendimento, além de i) abrir diferentes possibilidades de envolvimento de mais pessoas das comunidades para trabalhar nos empreendimentos, de acordo com suas disponibilidades; e ii) ter maior clareza das necessidades de formação técnica e profissional para o desenvolvimento do empreendimento, conferindo-lhes, por conseguinte, a garantia de seu trabalho em melhores condições.

É importante destacar também que a dimensão individual não é totalmente desconsiderada em uma organização cooperativa. $\mathrm{O}$ esforço e a criatividade individual seguem como fatores fundamentais para o desenvolvimento de um empreendimento dessa natureza. Ocorre que, sob o paradigma do trabalho associado, cada indivíduo passa a ser integrado em um coletivo que envolve diferentes funções e responsabilidades voltadas a finalidades comuns, com metas e normas, definidas conjuntamente, a serem seguidas por todos. O estatuto social e o regimento interno são os documentos principais que normatizam o trabalho coletivo, mas documentos como planos de negócio, planejamentos estratégicos, entre outros, também podem ser elaborados, desde que sejam submetidos ao escrutínio geral do grupo para aprovação. $\mathrm{O}$ fato de trabalharem em conjunto possibilita uma troca de informações mais intensa e a formação de um ambiente 
mais propício para a mobilização dos atores no intuito de reivindicar direitos e acesso a serviços públicos.

Entretanto, três coisas valem ser ressaltadas, pois se relacionam diretamente com a dimensão da autonomia do grupo. Primeiro, os catadores ainda enfrentam inúmeras dificuldades instrumentais (capacitação técnica, assessoria, subsídio financeiro, entre outras) na orientação de suas atividades, tendo em vista a constituição e manutenção de empreendimentos coletivos. Segundo, apesar da importância desse apoio, a relação entre entidade de assessoria (pública ou privada) com o empreendimento de catadores deve ser de parceria, baseada em um diálogo franco entre as partes, para que não gere expectativas exageradas nem constitua uma relação de extrema dependência por parte do empreendimento, ferindo assim sua autonomia. Por fim, a opção pela formação de um empreendimento cooperativo deve partir dos próprios associados, uma vez que a imposição do cooperativismo (seja por parte de uma política pública ou de uma entidade de apoio) dificulta a autonomia em relação a agentes externos e o funcionamento democrático interno, além de aumentar o risco de desmobilização do grupo, em caso de descontinuidade do projeto de apoio.

\section{Considerações finais}

Este artigo apresenta uma visão geral sobre a realidade dos empreendimentos coletivos formados por catadores de materiais recicláveis no Brasil, entre uma infinidade de outras abordagens possíveis. Todas as informações identificadas e analisadas demonstram que não apenas a profissão de catador é marcada por uma grande heterogeneidade, em termos de organização do trabalho, como seus empreendimentos econômicos coletivos também são bastante heterogêneos, sobretudo no que diz respeito a fatores como posse de maquinários e infraestrutura física, acesso a crédito e conhecimento técnico, local de atividade e tipos de produtos trabalhados, histórico de formação e critérios internos de funcionamento, tempo dedicado pelos cooperados e divisão interna de trabalho, processos de gestão, estabelecimento de parcerias, características das regiões em que se inserem, articulações em rede, entre outros.

Esse conjunto de fatores impacta diretamente no nível de eficiência econômica do trabalho dos catadores, no rendimento médio auferido por eles, nas condições de trabalho e sua intensidade, e, consequentemente, na satisfação dos catadores em fazer parte de um empreendimento coletivo. Por isso a dificuldade em se estabelecer um padrão geral da realidade socioceconômica dos empreendimentos desse setor, ainda mais se considerado o alto nível de informalidade que o caracteriza. Nesse sentido, entender essa heterogeneidade estrutural é fundamental para a definição de políticas e programas governamentais que valorizem a atividade dos catadores e incentivem sua organização coletiva, no intuito de fornecer-lhes as capacidades infraestruturais para o desenvolvimento de seus projetos.

Ficou evidente que a grande maioria dos empreendimentos coletivos de catadores de material reciclável se caracteriza por uma série de carências e 
problemas estruturais, o que aponta para um longo horizonte de lutas e trabalho para reverter esse quadro. O problema está em conseguir ajustar esse gap, já que esses trabalhadores vivem, em sua maioria, no limite de suas necessidades básicas, e contam apenas com a renda de seu trabalho para manter a si e suas famílias. Por isso, há uma dificuldade grande por parte deles em suportar esse tempo socialmente necessário para a viabilização de um empreendimento coletivo, a menos que outras atividades ou programas de apoio complementares auxiliem paralelamente na manutenção dos integrantes durante esse período.

Ainda assim, as dificuldades que, de uma maneira geral, atingem todos os empreendimentos econômicos informais no país, não apenas os de reciclagem, não impedem que haja um fortalecimento da proposta de organização coletiva dos catadores para o exercício de suas atividades. As experiências atuais já garantem trabalho e renda a um número significativo de famílias em todo o país, em que pese todos os desafios que ainda caracterizam o associativismo no Brasil. A constituição de organizações representativas nacionais, como o MNCR, e o surgimento de leis como a que instituiu a PNRS, despontam como perspectivas positivas importantes para novas conquistas e melhor articulação desses empreendimentos.

Além disso, tanto os desafios quanto as potencialidades desses empreendimentos são fortemente marcados pelas próprias desigualdades socioeconômicas que caracterizam o processo de desenvolvimento brasileiro. Uma análise mais aprofundada da realidade desses EES não pode deixar de levar em conta esses fatores.

\section{Referências}

ARIOLI, Inea G. S. Cooperativismo e economia solidária: a constituição de uma cooperativa de catadores de resíduos sólidos em São Joaquim/SC. Revista Otra Economia, v. 10, n. 19, 2016.

DAGNINO, Renato. Neutralidade da ciência e determinismo tecnológico: um debate sobre a tecnociência. Campinas: Ed. Unicamp, 2008.

DAGNINO, Ricardo S.; JOHANSEN, Igor C. Os catadores no Brasil: características demográficas e socioeconômicas dos coletores de material reciclável, classificadores de resíduos e varredores a partir do censo demográfico de 2010. Mercado de Trabalho: acompanhamento e análise, Rio de Janeiro, v. 23, p. 115-125, 2017.

DAMÁSIO, João. Para uma política de pagamento pelos serviços ambientais urbanos de cooperativas e associações de catadores de materiais recicláveis. Salvador: Pangea, 2010.

DEMOUSTIER, Daniele. A economia social e solidária. São Paulo: Loyola, 2006.

FÉ, Carlos F. C. M.; FARIA, Maurício S. Catadores de resíduos recicláveis: autogestão, economia solidária e tecnologias sociais. In: ZANIN, Maria; GUTIERREZ, Rafaela F. (orgs.). Cooperativas de catadores. São Carlos: Claraluz, 2011.

GAIGER, Luiz I. A economia solidária e a revitalização do paradigma cooperativo. Revista Brasileira de Ciências Sociais - RBCS, São Paulo, v. 28, n. 82, p. 211-228, 2013.

. A economia solidária no Brasil. São Leopoldo: Oikos, 2014.

GUTIERREZ; Rafaela F.; ZANIN, Maria. Empreendimentos econômicos de catadores de resíduos e legislações vigentes. Revista Interinstitucional de Psicologia, Juiz de Fora, v.4, n. 2, p. 113-121, 2011. 
INSTITUTO DE PESQUISA ECONÔMICA APLICADA - IPEA. Diagnóstico sobre catadores de resíduos sólidos. Relatório de Pesquisa. Brasília: Ipea, 2011.

LAVILLE, Jean-Louis. A economia solidária: um movimento internacional. Revista Crítica de Ciências Sociais, Lisboa, n. 84, p. 7-47, 2009.

LEITE, Maria P. A economia solidária e o trabalho associativo. Revista Brasileira de Ciências Sociais RBCS, São Paulo, v. 24, n. 69, p. 31-51, 2009.

LIMA, Jacob C. O trabalho autogestionário em cooperativas de produção. Revista Brasileira de Ciências Sociais- RBCS, São Paulo, n. 56, v. 19, p. 45-62, 2004.

MAGALHÃES, Beatriz J. Liminaridade e exclusão: os catadores de materiais recicláveis e suas relações com a sociedade brasileira. 2012. Dissertação (Mestrado em Antropologia) - Universidade Federal de Minas Gerais, Belo Horizonte, 2012.

NAGEM, Fernanda; SILVA, Sandro P. Institucionalização e execução das políticas públicas de economia solidária. Revista de Sociologia e Política, Curitiba, v. 21, n. 46, p. 159-175, 2013.

PEPINELLI, Rafaela F. G. Empreendimentos econômicos solidários de catadores. 2011. Dissertação (Mestrado em Ciência, Tecnologia e Sociedade) - Universidade Federal de São Carlos, São Carlos, 2011. PINHEL, Julio R. Do lixo à cidadania. São Paulo: Peirópolis, 2013.

SANTOS, Maria C. L. et al. Frames de ação coletiva: uma análise da organização do MNCR. In: SCHERER-WARREN, Ilse; LUCHMANN, Lígia H. H. Movimentos sociais e participação. Florianópolis: Ed. da UFSC, 2011.

SILVA, Sandro P. Entidades de apoio e fomento à economia solidária no Brasil. Mercado de Trabalho: acompanhamento e análise, v. 61, p. 107-116, out. 2016.

Análise das dimensões socioestruturais dos empreendimentos de economia solidária no Brasil. Texto para Discussão, n. 1945. Brasília: Ipea, 2017a.

O campo de pesquisa da economia solidária no Brasil: abordagens metodológicas e dimensões analíticas. Texto para Discussão, no prelo. Brasília: Ipea, 2017b.

SILVA, Sandro P.; CARNEIRO, Leandro M. Os novos dados do mapeamento de economia solidária no Brasil: nota metodológica e análise das dimensões socioestruturais dos empreendimentos. Relatório de Pesquisa, Ipea, 2016.

SILVA, Sandro P.; GOES, Fernanda L.; ALVAREZ, Albino. Situação social das catadoras e dos catadores de material reciclável. Brasília: Ipea, 2013.

SILVA, Sandro P.; NAGEM, Fernanda A. Dimensões estruturais dos empreendimentos de economia solidária. Revista Econômica do Nordeste, Fortaleza, v. 43, n. 2, p. 309-326, 2012.

SINGER, Paul. Introdução à economia solidária. São Paulo: Perseu Abramo, 2002.

ZANIN, Maria; GUTIERREZ, Rafaela F. (orgs.). Cooperativas de catadores. São Carlos: Claraluz, 2011. 